\title{
Adequação do layout para redução de desperdícios em uma empresa de embalagens
}

\author{
Layout adequacy to reduce waste in a packaging company \\ Ajuste del layout para reducir los residuos en una empresa de embalaje
}

Gabrielle Evangelista Gonçalves ORCID: https://orcid.org/0000-0002-5461-6375 Faculdade de Engenharia de Minas Gerais, Brasil E-mail: gabrielleeg.sp@gmail.com

Luis Felipe Silva

ORCID: https://orcid.org/0000-0002-4932-3375 Faculdade de Engenharia de Minas Gerais, Brasil E-mail: elleoluis@hotmail.com

Thais Tayane Martins Nobre ORCID: https://orcid.org/0000-0003-3836-3993 Faculdade de Engenharia de Minas Gerais, Brasil E-mail: thaismartins.nobre@gmail.com

Gabriela Gregorio

ORCID: https://orcid.org/0000-0001-9022-4005 Faculdade de Engenharia de Minas Gerais, Brasil E-mail: gabriela.fonseca@feamig.br

Tálita Rodrigues de Oliveira Martins ORCID: https://orcid.org/0000-0002-3850-5042 Faculdade de Engenharia de Minas Gerais, Brasil E-mail: talita22r@yahoo.com.br

\begin{abstract}
Resumo
As organizações procuram se manter em um mercado que está mais competitivo, junto a consumidores exigentes, com isso vem a importância de produzir com qualidade e manter um preço competitivo, uma das formas de se alcançar isso é através da eliminação de desperdícios, pois permite a organização a expandir sua lucratividade sem precisar aumentar o preço final do produto. Por este motivo, este trabalho tem como objetivo apresentar um layout mais adequado, para que seja possível melhorar o processo de produção de embalagens de papelão, a fim de cooperar com resultados satisfatórios no processo, como a eliminação dos desperdícios. Para atingir esse objetivo as seguintes ações foram realizadas: mapeamento do processo produtivo, identificação e quantificação dos desperdícios e sugestões de melhorias. $\mathrm{O}$ estudo de caso foi realizado em uma fábrica de embalagens de papelão localizada na cidade de Betim - MG e para a coleta e análise dos dados foram utilizadas as técnicas de um questionário com os funcionários e visitas in loco para observação.
\end{abstract}

Palavras-chave: Arranjo físico; Eliminação de desperdícios; Indústria de embalagens.

\begin{abstract}
Organizations seek to mantain them selfs in a market that is increasingly competitive, with increasingly demanding consumers, this comes with the importance of producing with quality and keep a competitive price. One of the ways to achieve this goal is through the elimination of waste, this allows the organization to increase its profitability without having to increase the final price of the product. For this reason, this study aims to present a more adequate layout, so that it is possible to improve the cardboard package production process, in order to cooperate with satisfactory results in the process, such as the elimination of waste. In order to achieve this objective, the following actions were carried out: mapping of the production process, identification and quantification of waste, and improvements suggestions. This case study was carried out in a cardboard packaging factory, located in the city of Betim - MG, and for data collection and analysis, semi-structured interview techniques on-site visits for observation and document analysis were used.
\end{abstract}

Keywords: Layout; Waste elimination; Packaging industry.

\section{Resumen}

Las organizaciones buscan permanecer en un mercado más competitivo, con consumidores exigentes, con esto viene la importancia de producir con calidad y mantener un precio competitivo, una de las formas de lograrlo es a través de la eliminación de desperdicios, ya que permite la organización. para ampliar su rentabilidad sin tener que incrementar el precio final del producto. Por ello, este trabajo tiene como objetivo presentar un layout más adecuado, de manera que sea posible mejorar el proceso de producción de envases de cartón, con el fin de cooperar con resultados satisfactorios 
en el proceso, como la eliminación de residuos. Para lograr este objetivo se realizaron las siguientes acciones: mapeo del proceso productivo, identificación y cuantificación de residuos y sugerencias de mejora. El caso de estudio se llevó a cabo en una fábrica de embalajes de cartón ubicada en la ciudad de Betim - MG y para la recolección y análisis de datos se utilizaron las técnicas de un cuestionario con empleados y visitas in situ para observación.

Palabras clave: Layout; Eliminación de resíduos; Industria del embalaje.

\section{Introdução}

A produção enxuta é uma das iniciativas que grandes empresas no Brasil buscam adotar para permanecerem competitivas em um mercado cada vez mais global. O principal foco da abordagem baseia-se na eliminação de desperdícios dentro de um sistema de manufatura, que visa diminuir custos e otimizar a produção em geral.

Desenvolvida por Taiichi Ohno na década de 1950, a busca contínua pela eliminação de desperdícios (conhecida como Sistema de Produção Enxuta) era a única forma de elevar a produtividade em um Japão pós-guerra. Ohno categorizou os desperdícios em sete tipos: desperdícios de superprodução, de movimentação desnecessária, de espera, em transporte, do processamento em si, de estoque e de produzir produtos defeituosos (Ohno,1997).

Basicamente, desperdício é qualquer atividade que consome recursos, mas não agrega valor ao cliente final, ou seja, toda atividade que não interfere na qualidade, ou atribui valor ao produto. Tais atividades podem diminuir a lucratividade, aumentar o custo final e até diminuir a satisfação dos funcionários. É por isso que as empresas se veem na necessidade de se concentrar na redução de atividades desnecessárias, melhorando o processo em que elas aparecem ou, preferencialmente, eliminando-as. Ao fazê-lo, pode-se identificar oportunidades significativas para melhoria de desempenho geral.

O arranjo físico ou layout, também faz parte da melhoria de eficácia do sistema de produção enxuta, trata-se da disposição ordenada e adequada das instalações de fabricação e do uso dos recursos disponíveis, incluindo mão de obra, maquinário, ferramentas e materiais.

O layout de uma empresa, ou arranjo físico, é o posicionamento dos bens transformadores e de movimentação de uma empresa, tais como: máquinas, equipamentos e as pessoas que atuam na organização. A realização de um bom layout dá-se por meio das caraterísticas e especificações do produto. (Vânia, et al., 2019, p. 3)

Quando bem projetado, o layout ajuda a visualizar e, consequentemente, eliminar alguns dos desperdícios citados anteriormente, como: estoque, movimentação desnecessária, a superprodução, o tempo de espera e de transporte. Em suma, um layout bem projetado diz respeito a utilização máxima e eficaz dos recursos disponíveis, a custos operacionais mínimos.

Neste cenário, este trabalho foi realizado com o intuito de analisar e avaliar o layout existente, e propor o melhor e mais eficaz arranjo físico para a empresa com base nos critérios relacionados à desperdício.

\subsection{Contexto do problema}

O setor de embalagens está relacionado diretamente ao poder de consumo da população, sendo bastante influenciado pela atividade econômica do país. Segundo Luciana Pellegrino, diretora executiva da Associação Brasileira de Embalagem (ABRE) às ações do mercado estão mudando cada vez mais rápido, e a "indústria tem entendido a tendência e se adequado para atender à demanda". (Soares, 2019)

Entretanto, com a elevação do custo da matéria-prima e de insumos, devido às incertezas da economia brasileira, houve um impacto negativo sobre os produtos de embalagem. Ao observar a situação de variabilidade no segmento, notou-se que para permanecer no mercado é importante atentar-se aos custos de produção que podem ser evitados. Com isso, buscam-se novas formas de gerenciamento do processo, e uma das opções que contribui para isso é adequação do arranjo físico.

Na fábrica de embalagens de papelão que foi estudada, notou-se problemas comuns no processo de produção, que é a 
perda de matéria prima no processo de corte e o estoque em processo. Dessa forma, se faz necessário investigar melhor as causas desses desperdícios e os impactos gerados para a empresa.

Outro desperdício identificado é o tempo de ajustes nas máquinas que ocorrem durante os processos de corte, e por ser um processo necessário é importante encontrar soluções para reduzir esse problema.

Sendo assim, buscar minimizar ou eliminar os desperdícios presentes no processo produtivo através de um layout adequado é importante para a competitividade da empresa. Para isso, deve-se identificar os pontos críticos desses desperdícios e analisar a melhor solução de arranjo físico.

\subsection{Problema de pesquisa}

Como adequar o layout de uma fábrica de embalagens de papelão, a fim de reduzir os desperdícios no sistema de produção?

\subsection{Objetivos}

\subsubsection{Objetivo geral}

Desenvolver um plano de adequação de layout visando a redução de desperdícios gerados no sistema de produção de embalagens de papelão, propondo formas para torná-lo mais enxuto.

\subsubsection{Objetivos específicos}

- Apresentar o layout atual adotado no processo produtivo;

- Identificar e quantificar os desperdícios encontrados no processo produtivo;

- Identificar as causas dos desperdícios no processo produtivo de embalagens de papelão;

- Propor as alterações no layout para reduzir os desperdícios identificados no processo produtivo.

\subsection{Justificativa}

A reestruturação do arranjo físico é considerada uma importante estratégia de mudança que favorece o alcance de melhorias na produção, pois se estiver incorreto pode resultar em retrabalhos, o que contribui para diversas formas de desperdícios no processo de produção existente, o que se torna menos competitivo no mercado.

Neste cenário, percebeu-se a necessidade de reajustar o arranjo físico, de forma que se faça alcançar os benefícios esperados no desempenho da produção, que ganha destaque na empresa em estudo, a fim de tornar o sistema de produção mais enxuto. Com isso, pretende-se analisar os desperdícios existentes no layout atual, para que esses possam ser reduzidos ou eliminados.

Em relação ao processo produtivo é importante considerar importantes atribuições que um engenheiro de produção pretende alcançar, não se restringindo apenas na melhoria do layout em uma empresa, mas também contribuir para diminuir os desperdícios existentes na indústria e melhorar os ciclos dos processos produtivos.

Por fim, com o intuito de redução dos desperdícios, além de agregar valor à cadeia produtiva respeitando os quesitos do meio ambiente, a empresa visa o reaproveitamento das sobras de embalagens, que seriam descartados, cooperando assim diretamente com o meio ambiente e beneficiando a sociedade.

Sendo assim, todas as intervenções realizadas permitirão que o cliente tenha uma série de produtos com custos mais acessíveis, onde cada decisão tomada com foco na redução de desperdício beneficiará todo o processo produtivo. 


\section{Metodologia}

\subsection{Pesquisa quantos aos fins}

De acordo com Gil (2002), ao longo do processo, a pesquisa passa por diversas fases, desde a formulação do problema até a apresentação dos devidos resultados. Ainda segundo o autor, a pesquisa é desenvolvida através de conhecimentos, métodos, técnicas e outros procedimentos científicos que tem como o propósito identificar problemas quando não se tem informações suficientes disponíveis ou se encontra desorganizada de tal modo que não consiga ser relacionada ao problema de forma clara.

Segundo Prodanov e Freitas (2013), existem dois tipos de pesquisa científica:

- Pesquisa básica que é focada em melhorar e gerar novas teorias científicas baseada na especulação.

- Pesquisa aplicada que procura resolver problemas concretos e tem por finalidade métodos na prática. É chamada também de pesquisa empírica, pois o pesquisador precisa ir a campo para conversar com as pessoas e presenciar as relações sociais.

Nesta circunstância, o presente trabalho foi uma pesquisa aplicada, à medida que buscará identificar desperdícios reais do processo de produção de embalagens e construir propostas para reduzi-los na prática.

Ainda, de acordo com Gil (2002) é possível agrupar as mais diversas pesquisas em três níveis. A seguir, serão apresentadas as diferentes maneiras de classificar e nomear as pesquisas quanto aos fins.

\subsubsection{Exploratória}

Segundo Gil (2002), a pesquisa exploratória tem como objetivo tornar as ideias e as descobertas de intuições mais compreensíveis, para formular o problema com mais precisão ou construir hipóteses. Este tipo de pesquisa pode envolver: “(a) levantamento bibliográfico; (b) entrevistas com pessoas que tiveram experiências práticas com o problema pesquisado; e (c) análise de exemplos que "estimulem a compreensão" “(Seltiz et al., 1967, p. 63 apud Gil, 2002, p.41).

\subsubsection{Descritiva}

A pesquisa descritiva é baseada em assuntos teóricos que envolvem técnicas de observação do problema, levantamento de dados com opiniões distintas, utilização de questionários, análise dos registros e relacionando determinadas variáveis através de um estudo comparativo e interpretação dos dados sem nenhuma interferência de quem realiza a pesquisa (Gil, 2002).

Entre as pesquisas descritivas, salientam-se aquelas que têm por objetivo estudar as características de um grupo: sua distribuição por idade, sexo, procedência, nível de escolaridade, estado de saúde física e mental etc. Outras pesquisas deste tipo são as que se propõem a estudar o nível de atendimento dos órgãos públicos de uma comunidade, as condições de habitação de seus habitantes, o índice de criminalidade que aí se registra etc. São incluídas neste grupo as pesquisas que têm por objetivo levantar as opiniões, atitudes e crenças de uma população. (Gil, 2002, p. 42)

\subsubsection{Explicativa}

Segundo Severino (2016), a pesquisa explicativa é aquela que, além de registrar e analisar os fenômenos estudados, busca identificar suas causas, seja através da aplicação do método experimental/matemático ou através da interpretação possibilitada pelos métodos qualitativos.

Essas pesquisas têm como preocupação central identificar os fatores que determinam ou que contribuem para a ocorrência dos fenômenos. Esse é o tipo de pesquisa que mais aprofunda o conhecimento da realidade, porque explica 
a razão, o porquê das coisas. Por isso mesmo, é o tipo mais complexo e delicado, já que o risco de cometer erros aumenta consideravelmente. (Gil, 2002, p.42)

Considerando os tipos de pesquisas quanto aos fins supracitados, a presente pesquisa foi classificada como exploratória, pois além de relacionar causa e efeito de potenciais desperdícios existentes no processo de produção de embalagens, construirá propostas para que estes desperdícios sejam minimizados.

\subsection{Pesquisa quanto aos meios}

Segundo Gil (2002), as pesquisas quanto aos meios podem ser classificadas em:

- Pesquisa bibliográfica: é desenvolvida baseadas em livros, artigos acadêmicos, teses e outros tipos de documentos que seja possível retirar citações que complementam a pesquisa, na qual chega em conclusões inovadoras a partir de fontes bibliográficas.

- Pesquisa de campo: realiza a aplicação de questionários e entrevistas através de observação direta, a fim de captar explicações e interpretações que ocorra dentro de algum grupo de trabalho, de estudo ou de lazer, e que não necessariamente precise ser geográfica. Ela também pode ser conjugada através de análise de documentos, filmagens e fotografias.

- Pesquisa-ação: detecta um problema coletivo, elabora um projeto e aplica junto ao grupo e depois avalia os resultados de uma forma que seja participativo e cooperativo.

- Estudo de caso: analisa profundamente os objetos a fim de identificar as características detalhadas da pesquisa. O estudo de caso é utilizado quando o pesquisador analisa um conjunto de acontecimentos sobre o qual tem pouco ou nenhum controle, evidenciando-os entre o contexto da vida real e o fenômeno. De acordo com Yin (2001), o estudo de caso pode ser classificado em: casos únicos, no qual se refere a projetos comuns para realização de estudos envolvendo somente um contexto e os casos múltiplos que envolvem mais de um contexto.

O estudo de caso conta com muitas das técnicas utilizadas pelas pesquisas históricas, mas acrescenta duas fontes de evidências que usualmente não são incluídas no repertório de um historiador: observação direta e série sistemática de entrevistas. Novamente, embora os estudos de casos e as pesquisas históricas possam se sobrepor, o poder diferenciador do estudo é a sua capacidade de lidar com uma ampla variedade de evidências documentos, artefatos, entrevistas e observações - além do que pode estar disponível no estudo histórico convencional. (Yin, 2001, p. 27)

Quanto aos meios, este trabalho se enquadra em um estudo de caso, uma vez que foi estudada de forma aprofundada os possíveis desperdícios encontrados no layout do processo de produção de embalagens de papelão de uma fábrica situada na cidade de Betim/MG, combinando além de dados históricos, uma ampla variedade de evidências como entrevistas e observações. Além disso, por ser tratar de um estudo de caso, os resultados gerados podem não se adequar a realidade de outras organizações.

\subsection{Organização em estudo}

A empresa em estudo, que neste trabalho será denominada de "Y"1 é uma indústria de embalagens de médio porte, com 140 colaboradores no total. À qual atua no mercado de embalagens de papelão desde 2007 e está instalada em uma sede própria, localizada na cidade de Pirapora do Bom Jesus em São Paulo, mas também foca parte da sua produção e o seu centro de distribuição na cidade de Betim em Minas Gerais.

O estudo de caso foi focado na unidade de Betim em Minas Gerais, na qual dispõe de 26 funcionários e possui clientes

\footnotetext{
${ }^{1} \mathrm{Y}$ é o nome fictício, pois a fábrica de embalagens estudada nesta pesquisa não permitiu o uso de seu nome.
} 
na região metropolitana de Belo Horizonte, como fabricantes de autopeças, de automóveis, de produtos eletroeletrônicos, colchões, móveis, entre outros, além de distribuir para outras regiões a nível nacional.

A empresa produz em média 500 toneladas por mês de diversos modelos de embalagens de papelão ondulado; micro ondulado, papel cartão, polionda e embalagens híbridas de papelão e madeira, com impressão flexográfica ou impressão offset. O seu processo de produção pode ser dividido em impressão, corte e vinco, dobra, colagem e armação da caixa.

\subsection{Universo e amostra}

Para se aplicar a organização em estudo, segundo Marconi e Lakatos (2003), é necessário que os métodos e técnicas utilizadas na pesquisa científica sejam analisados e reconhecidos delimitando o universo e amostra.

O universo ou população, segundo Silva e Menezes (2005), é definido como agrupamento de indivíduos que a pesquisa visa representar através de resultados para um determinado estudo. Ainda segundo os autores, a amostra pode ser esclarecida como a composição de indivíduos que irão fazer parte da pesquisa dentro do universo ou população estudados.

Para este trabalho, o universo é a unidade da empresa produtora de embalagens situada na unidade de Betim, e a amostra fez parte do processo produtivo, integrada pelas seguintes operações: impressão, na qual dispõe de 04 operadores na estação de trabalho, corte e vinco com 04 operadores, dobra e colagem com 05 operadores e armação da caixa com 02 operadores.

\subsection{Formas de coleta e análise de dados}

Para Zanella (2009), coleta de dados pode-se dispor de questionários, análise de documentos, observações e entrevistas, que podem ser utilizados individualmente ou combinados. Abaixo serão apresentados alguns tipos de coleta de dados:

- Questionários: é uma ferramenta composta por uma série ordenada de perguntas que podem ser chamadas de descritivas, quando o objetivo é identificar o perfil das pessoas entrevistadas, como idade, renda, escolaridade e profissão; comportamentais que tem o propósito de conhecer o comportamento do entrevistado, como padrão de consumo, comportamento social e econômico; e por fim de preferenciais, que busca avaliar a opinião do entrevistado em relação ao problema da pesquisa (Zanella, 2009).

- Análise documental: segundo Zanella (2009), envolve a identificação dos documentos internos, como o estatuto, regulamento, relatórios e manuais, ou dos documentos externos (governamentais, de organizações não-governamentais ou instituições de pesquisa, dentre outras). É uma técnica utilizada tanto em pesquisa quantitativa como qualitativa.

- Observação: "é uma técnica científica que utiliza o sentido visual para obter informações da realidade" (Zanella, 2009, p.121). É utilizada na pesquisa, pois capta diretamente o fenômeno sem a interatividade de um documento ou de um interlocutor. A observação pode ser classificada em: observação assistemática, no qual não segue um planejamento de maneira antecipada; observação sistemática, onde é elaborado um plano específico e estabelece antecipadamente as necessidades para análise de cada situação; observação não participante, no qual o pesquisador mantém distância dos eventos, atua como espectador; e observação participante, onde o observador assume o papel de um membro do grupo e participa de sua atuação (Zanella, 2009).

- Entrevista: é utilizada para obter informações de um determinado assunto através da perspectiva do entrevistado. De acordo com Silva e Menezes (2005), as entrevistas podem ser: estruturada, com roteiro previamente estabelecido; ou semiestruturada, no qual não exige rigidez de roteiro.

O presente estudo de caso combinou três formas principais de coleta de dados, sendo elas: observação sistemática, análise documental e a entrevista semiestruturada.

A observação sistemática teve como objetivo o melhor entendimento do processo produtivo e proporcionou a 
identificação de alguns desperdícios que incidem sobre o processo. Para isto, foram realizadas 02 visitas in loco, pelos três integrantes do grupo, no segundo semestre de 2020, onde as informações sobre o produto, os processos produtivos e o layout da fábrica foram registrados.

$\mathrm{Na}$ análise documental, frequentemente usada devido às várias maneiras de apoiar e fortalecer a pesquisa, foram verificados documentos como: relatórios de controle de estoque e de desperdícios de insumos. Os documentos que foram analisados, tiveram o período de um ano, sendo de janeiro de 2019 a janeiro de 2020, pois pode ocorrer algumas sazonalidades que influenciam nos desperdícios, como o aumento ou a redução da produção.

Já a entrevista semiestruturada foi realizada através de 01 visita in loco, no segundo semestre de 2020. Foi selecionada uma amostra de 70\% dos funcionários, sendo aplicadas as entrevistas para 01 funcionário do nível estratégico, 02 funcionários do nível tático e 15 funcionários do nível operacional. As respostas foram redigidas manualmente, com a participação dos 3 integrantes do grupo. Por meio da entrevista foram identificadas informações sobre o processo produtivo, causas dos desperdícios e a percepção dos funcionários quanto a oportunidades de melhorias para a redução desses desperdícios.

A partir desta abordagem, a análise de dados foi quantitativa e qualitativa. De acordo com Zanella (2009), a análise quantitativa utiliza o conhecimento estatístico para duas finalidades: descrever, no qual apresenta graficamente os dados de pesquisa; e testar hipóteses para identificar e caracterizar relações entre variáveis.

Já a análise qualitativa, de acordo com Vergara (2016), é exploratória, ou seja, visa extrair dos entrevistados seus pensamentos que foram livremente ditos sobre algum tema, objeto ou conceito. A análise qualitativa buscou compreender a perspectiva do entrevistado e para atender esse objetivo é utilizado a técnica de análise de conteúdo, no qual trabalha com materiais textuais, como entrevistas e os registros das observações.

Para análise dos dados foram utilizadas ferramentas como o software Mini-tab para criar fluxogramas, folha de verificação e o gráfico de Pareto, em conjunto com o Excel a fim de quantificar e analisar os desperdícios observados. Assim, torna-se possível a elaboração de relatórios que auxiliam no controle de estoque e desperdícios de insumos, que servirão de parâmetros para analisar quantitativamente os desperdícios observados dentro da empresa, assim como compreender suas causas e, eventualmente, propor medidas para diminuí-los e/ou eliminá-los.

\subsection{Limitações da pesquisa}

Umas das limitações que podem ocorrer ao longo do trabalho foi em relação a coleta de dados, pois deve-se considerar a confiabilidade dos dados obtidos através de documentos da empresa. É possível também encontrar dificuldades para entrevistar o nível estratégico, uma vez que a maioria se encontra na sede principal da empresa, em São Paulo. Outra possível limitação desta pesquisa se refere a impossibilidade de visitas físicas, devido a pandemia causada pelo COVID-19.

\section{Resultados e Discussão}

$\mathrm{Na}$ análise e discussão dos resultados, realizou-se a aplicação dos conceitos e ferramentas apresentados no referencial teórico para elaboração de proposta para um novo layout para a empresa em questão.

Começando pela apresentação, categorização e mapeamento do layout atual dos processos produtivos e dos fluxos internos atuais, a fim de identificar pontos críticos e desperdícios ao longo de todo o processo.

Em seguida, será apresentada a proposta de layout, elaborada com base no tipo de processo utilizado pela empresa, e por fim, serão apresentados algumas das vantagens que podem ser alcançadas com a implementação do layout proposto 


\subsection{Layout atual do processo produtivo de embalagem de papelão adotado pela empresa}

Parte importante da estratégia de produção da empresa é a personalização de seus produtos, ou seja, todas as especificações técnicas, desde o tipo de material usado até as dimensões da embalagem são definidas previamente pelo cliente. Como resultado, grande parte do mix de produtos não tem um roteiro de produção definido, uma vez que os produtos são fabricados por grupos ou quantidades específicas.

Para conseguir lidar com o alto fluxo de produção e as especificações, variando produto a produto, o processo produtivo utilizado é o em lotes. Nesse sistema, em vez de produzir itens de forma contínua ou individual, a produção se move em grupos ou lotes. Como apontam Slack, Chambers \& Johnston (2002), esse processo pode ser utilizado para um gama mais amplo de níveis de volume e variedade do que os outros tipos de processos.

O lote de embalagens pode passar por uma série de etapas para produzir o produto final desejado. Cada uma das etapas do processo de produção é aplicada ao mesmo tempo a um lote completo de itens. Esse lote não passa para a próxima etapa do processo de produção até que todo o lote seja produzido. As etapas estão descritas no Quadro 1.

Quadro 1 - Etapas do processo produtivo de embalagem de papelão.

\begin{tabular}{|c|c|}
\hline Transporte & $\begin{array}{c}\text { Ao iniciar o processo de fabricação, as caixas são transportadas } \\
\text { manualmente da armazenagem para próximo a máquina de vinco para iniciar a } \\
\text { prodũo. }\end{array}$ \\
\hline Vinco & No processo de corte e vinco é definido o formato da caixa a qual será \\
fabricada.
\end{tabular}

Fonte: Autores (2021).

Para um melhor entendimento a respeito do fluxo do processo produtivo das embalagens de papelão, foi feito o mapeamento geral para análise de acordo com sua ordem de fabricação. Utilizou-se o fluxograma (Figura 1) para identificar como o processo é realizado dentro da empresa. 
Figura 1 - Fluxograma Processo Produtivo da Caixa de Papelão.

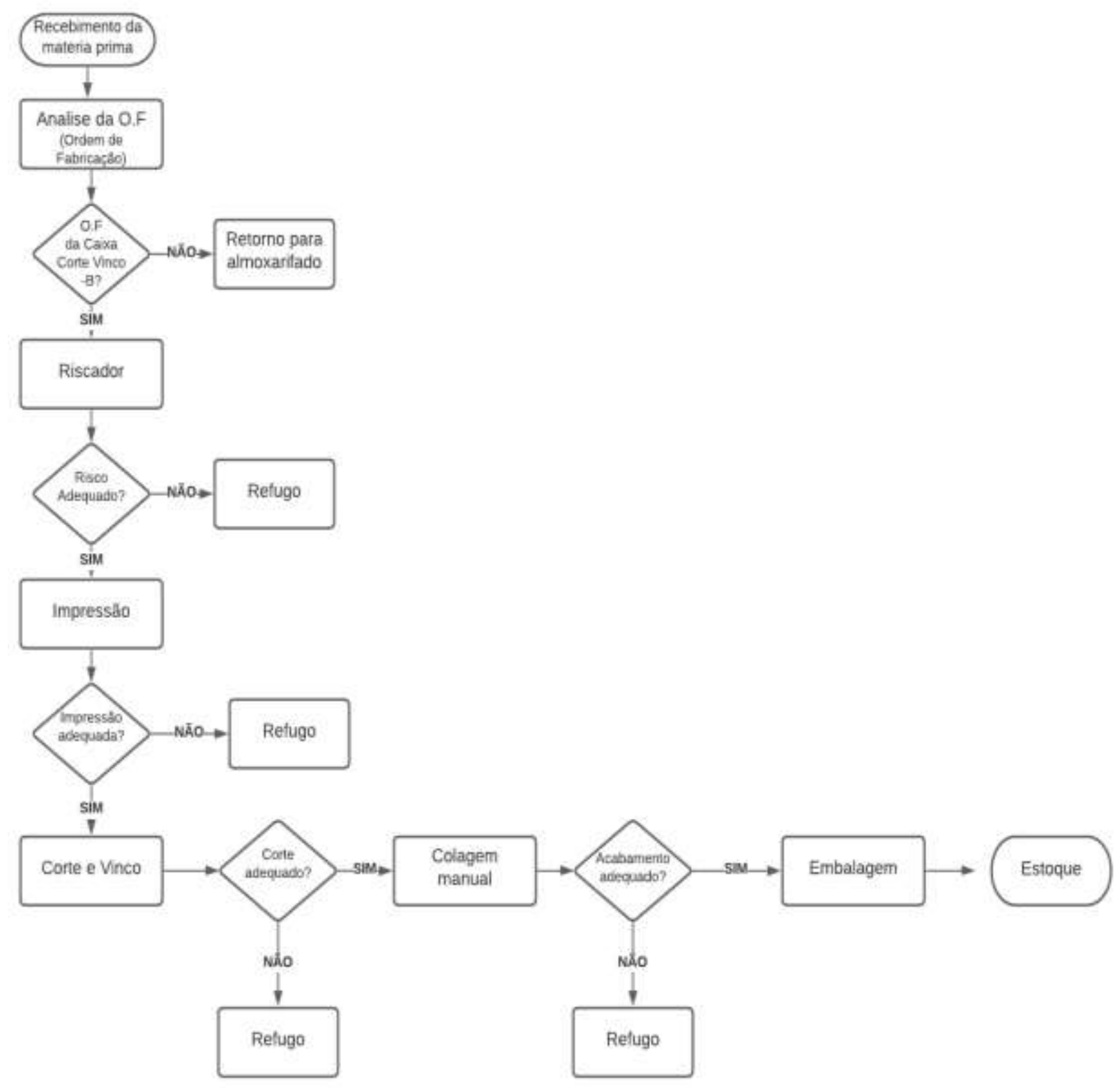

Fonte: Autores (2021).

Conforme demonstrado, o processo inicia-se com a matéria-prima recebida e estocada. Em seguida, através do recebimento da Ordem de Fabricação (O.F), o operador transporta através da empilhadeira as respectivas chapas de papelão para a máquina de riscador, onde as chapas ficam estocadas ao lado da máquina aguardando o processamento, conforme descrito na ordem de fabricação da empresa.

Após verificação, o operador transporta as chapas devidamente marcadas para o setor de impressão, no qual recebem a estampa impressa. Esse processo é realizado em uma máquina Impressora Flexográfica, conforme descrito na Ordem de Fabricação (O.F), de acordo com as especificações do cliente. Durante todo o processo verifica-se constantemente a qualidade do material.

Após a impressão, encaminha-se para o setor de corte e vinco. Nesta etapa, o operador programa a máquina para definir o formato da caixa, de acordo com as especificações do cliente. Ao final desta etapa as caixas são averiguadas para seguir para 
a próxima etapa.

$\mathrm{Na}$ etapa seguinte ocorre o processo de Colagem. Esse processo é realizado com uma cola especial ou por intermédio de grampos metálicos específicos. Trata-se de uma operação manual, realizada caixa a caixa. Após verificação e conformidade esse processo encerra a produção das caixas.

O lote é então empilhado, distribuído em pallets e estocado para ser despachado e entregue ao cliente. Os refugos são recolhidos e transportados por empilhadeiras até o exterior do galpão, onde passam por uma prensa hidráulica, a fim de diminuir o volume para o armazenamento, e posteriormente vendido à indústria que recebe os refugos para reciclagem.

Todas essas etapas, muitas das quais nem sempre utilizadas em todos os produtos, criam a necessidade de um layout com maior flexibilidade para adaptar-se a vários produtos, pois desta forma, as operações de tarefas possuem certa independência, como corroboram Peinado e Graeml (2007).

Figura 2 - Layout atual da empresa de embalagens de papelão.

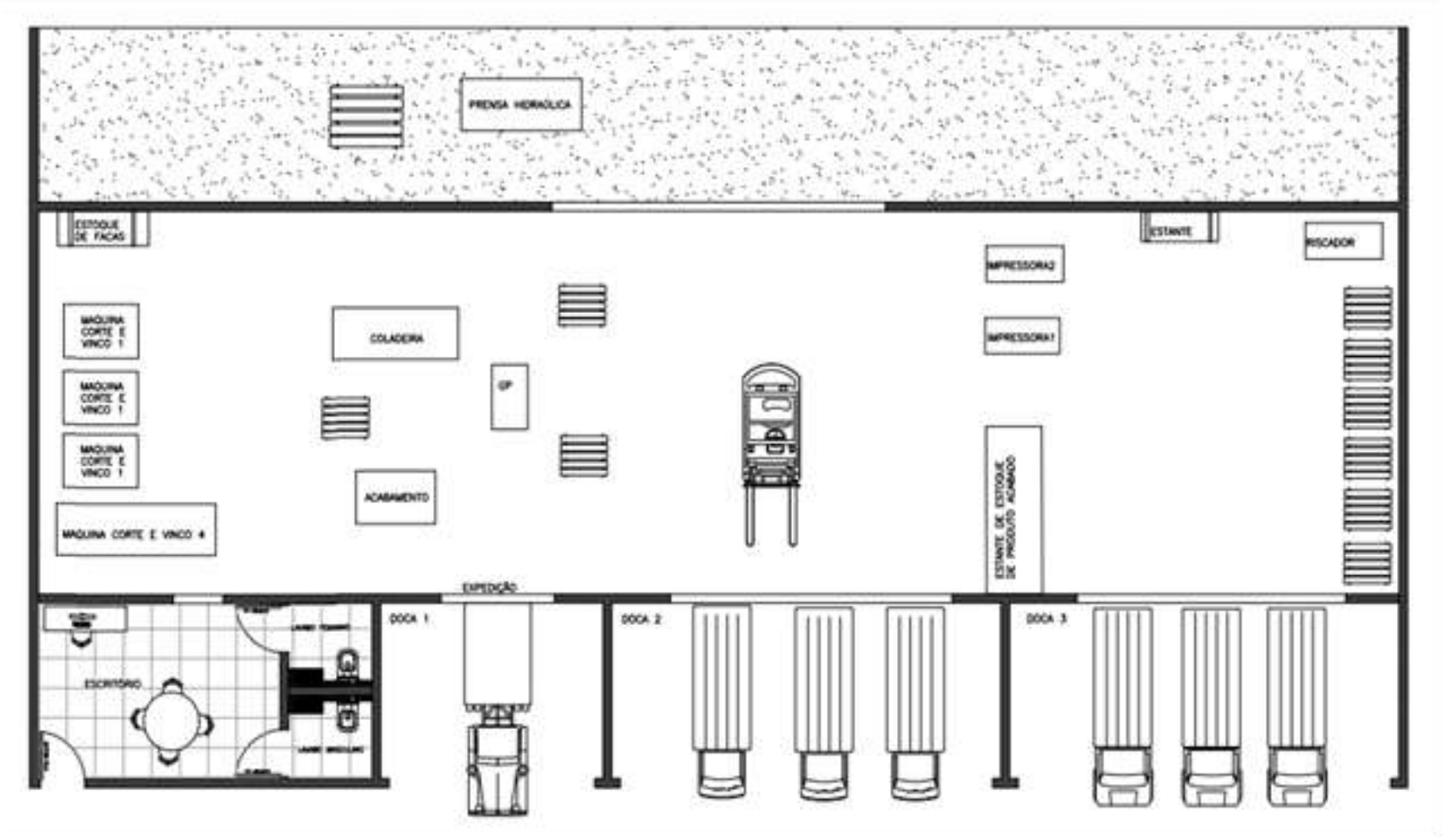

Fonte: Autores (2021).

Por meio da Figura 2, pode-se afirmar que o layout atual é o por processo, como definido por Slack, Chambers \& Johnston (2002). Neste tipo de layout, são agrupados em uma mesma área todos os equipamentos e processos similares. Os diferentes tipos de produtos são encaminhados a determinada área de tarefas, onde existem o mesmo tipo de máquina, de acordo com suas necessidades.

A primeira consideração a ser feita acerca do layout atual diz respeito à localização do maquinário, que foi adaptado para a produção sem a realização de um estudo adequado de layout para favorecer o fluxo de pessoas, matéria-prima e produtos. Por exemplo, a empresa não possui nenhum fluxograma, mapa da fábrica, processos operacionais padrão, dentre outros.

Embora a divisão entre as áreas não seja clara, contando apenas com uma placa, presa ao teto, que informa o tipo do grupo de máquinas, existem também, áreas sem uso, assim como espaços com excesso de materiais. 
Não existem demarcações para os centros de trabalho, nem para indicar os corredores de circulação, tendo um mau aproveitamento da área, o que torna o fluxo confuso e prejudica o processo produtivo. Não há um padrão determinado para o fluxo das embalagens em produção dentro do processo, dificultando o controle visual e a toda a organização da fábrica. Para uma melhor análise, fez-se necessária a identificação e quantificação dos desperdícios existentes para então realizar uma proposta nova de layout.

\subsection{Identificação e quantificação dos desperdícios existentes no processo produtivo mapeado}

Para definir e propor a elaboração de uma proposta de novo layout para a empresa em questão, foi necessário percorrer toda a fábrica coletando informações, identificando e observando as perdas existentes no processo atual. A base para esta análise são os sete tipos de perdas, citados anteriormente por Antunes et.al (2008) dentro do sistema de produção enxuta, que são: perdas por superprodução; perdas por movimentação; perdas por espera; perdas por transporte; perdas por processamento; perdas por estoque e perdas por fabricação de produtos defeituosas.

No presente estudo foram verificados os sete tipos de desperdícios através do questionário aplicado aos funcionários. Após a apuração dos resultados, foi possível desenvolver uma análise mais detalhada destes desperdícios. O questionário aplicado forneceu uma visão mais ampla dos desperdícios sendo percebidos pelos próprios operadores, de acordo com Quadro 2.

Quadro 2 - Folha de Verificação.

\begin{tabular}{|l|c|c|c|c|c|c|c|c|}
\hline \multicolumn{1}{|c|}{ ÁREA } & \multicolumn{7}{|c|}{ DELHA DE VERIFICAÇ̃̃O } & \multirow{2}{*}{ TOTAL } \\
\cline { 2 - 10 } & DEFEITO & SUPERPRODUÇÃO & ESTOQUE & ESPERA & TRANSPORTE & MOVIMENTAÇÃo & PROCESSAMENTO & \\
\hline Acabamento & 12 & 13 & 8 & 5 & 8 & 4 & 8 & 58 \\
\hline Coladeira & 2 & & & 2 & 2 & 2 & & 8 \\
\hline Corte e vinco & 3 & 3 & 2 & 1 & & & 1 & 10 \\
\hline Grampeadeira & 2 & 1 & 1 & 1 & 2 & 1 & & 8 \\
\hline Impressora & 2 & & & 2 & 2 & & & 6 \\
\hline TOTAL & 21 & 17 & 11 & 11 & 14 & 7 & 9 & 90 \\
\hline
\end{tabular}

Fonte: Autores (2021).

Ao analisar os dados apresentados no Quadro 2, foi possível verificar que a perda por fabricação de produtos defeituosos foi citada por todos os setores. Este tipo de desperdício citado por Imai (2014), é relacionado à fabricação de produtos fora da especificação de qualidade e conformidade requerida, gerando retrabalhos na produção. No setor de acabamento foi mencionada a chapa de papelão com defeito, impressão e marcação errada, o que só é percebido pelo setor de acabamento depois que passa por todos os setores como, coladeira, impressão, corte e vinco e grampeadora.

A perda por superprodução foi citada nas etapas de acabamento, corte e vinco e grampeadeira. Essa perda se dá devido a produção de caixas a mais do que o programado para uma possível próxima compra do cliente, o que gera estoque. Conforme aponta Shingo (2007), a superprodução é ocasionada quando o lote produz quantidade maior do que o especificado pela ordem de fabricação.

A perda por estoque é citada nos setores de acabamento, corte e vinco e grampeadeira. A falta de controle é relatada pelos trabalhadores que citam a existência de estoques elevados de produto acabado. Foram identificados estoques provisionados pela gestão devido a manter um estoque de segurança no local caso haja solicitação antecipada pelos clientes. Antunes et. al. (2008), aponta está como sendo uma das principais características desse tipo de desperdício, um resultado da superprodução.

A perda por movimento ocorre nos setores de acabamento, coladeira e impressão. Devido a movimentação interna de 
materiais acontecer pelo próprio trabalhador que opera o maquinário, onde são retiradas a matéria prima do armazenamento e colocado em um pallet de espera próximo à máquina.

Conforme citado por Imai (2014), as perdas no movimento estão diretamente ligadas ao esforço que o trabalhador faz para realizar atividades de uma operação, como por exemplo, carregar ou levantar objetos pesados.

Já a perda por transporte foi citada nos setores de acabamento, coladeira, grampeadeira e impressora. Esse tipo de perda se dá devido à disposição inadequada dos refugos de papelão próximos às máquinas que ficam aguardando o transporte para o exterior da fábrica, que além de dificultar a passagem dos trabalhadores, podem ocasionar acidentes internos. De acordo com Imai (2014), todos os processos devem ficar próximos da linha de produção para evitar o deslocamento desnecessário dos produtos, materiais, entre outros insumos.

Por fim, a perda por espera é mencionada em todos os setores, pois permanecem um intervalo de tempo aguardando a produção das embalagens ou esperam pelo ajustamento das placas de corte que necessariamente é realizado pelo trabalhador. Segundo Antunes et al. (2008) as perdas por espera estão ligadas ao alto tempo de preparação das máquinas, falta de sincronização do material na produção. E para isso é necessário um sistema de gestão como o Kanban para aplicar as correções necessárias ligadas a esse tipo de desperdício, realizando então operações em paralelos a outras atividades, criação de processos rápidos e ajustamentos rápidos das máquinas para que seja alcançado a maior produtividade dos maquinários.

Para melhorar esta realidade com base na análise da folha de verificação, elaboramos o gráfico de Pareto, no qual se evidencia as perdas de maior frequência, conforme Gráfico 1.

Gráfico 1 - Gráfico de Pareto dos tipos de desperdícios.

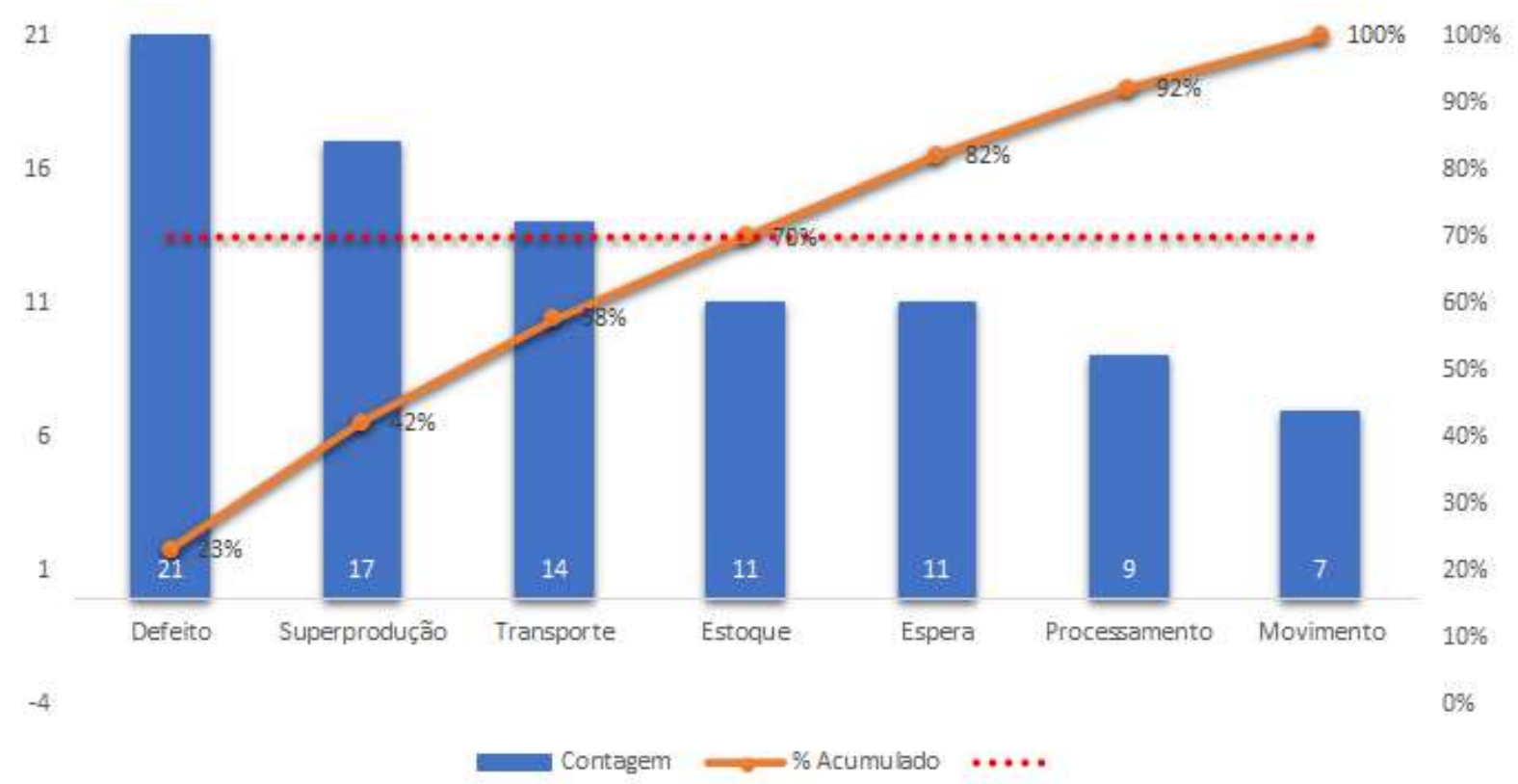

Fonte: Autores (2021).

Na folha de verificação tem-se uma visão por setor dos desperdícios, já com o gráfico de Pareto, ou diagrama de Pareto, tem uma visão geral dos desperdícios, e com esse resultado sabe-se em quais os desperdícios deve-se priorizar nossos esforços, como definido por Werkema (2013). Assim, tendo uma visão quantitativa de quão impactantes cada um desses desperdícios é.

Ao analisar e interpretar o gráfico, pode-se observar que a perda por defeito é a principal causa de reclamações e deve ser priorizada. As 4 perdas que se ouve mais insatisfação representam 70\% das ocorrências de reclamações, são elas: perdas por defeito, superprodução, transporte e estoque. 
As demais perdas também precisam ser tratadas, mas ao solucionar as perdas prioritárias, temos um impacto maior na melhoria da qualidade do processo e, consequentemente, na redução de custos.

\subsection{Causas dos desperdícios no processo produtivo de embalagens de papelão}

Através do gráfico de Pareto constatou-se os desperdícios de maior ocorrência, que são: Perdas por defeitos; por transporte; por estoque e por superprodução. A seguir será verificado as causas de tais perdas, como mostra o Diagrama de Ishikawa representado na Figura 3.

Figura 3 - Diagrama de Ishikawa.

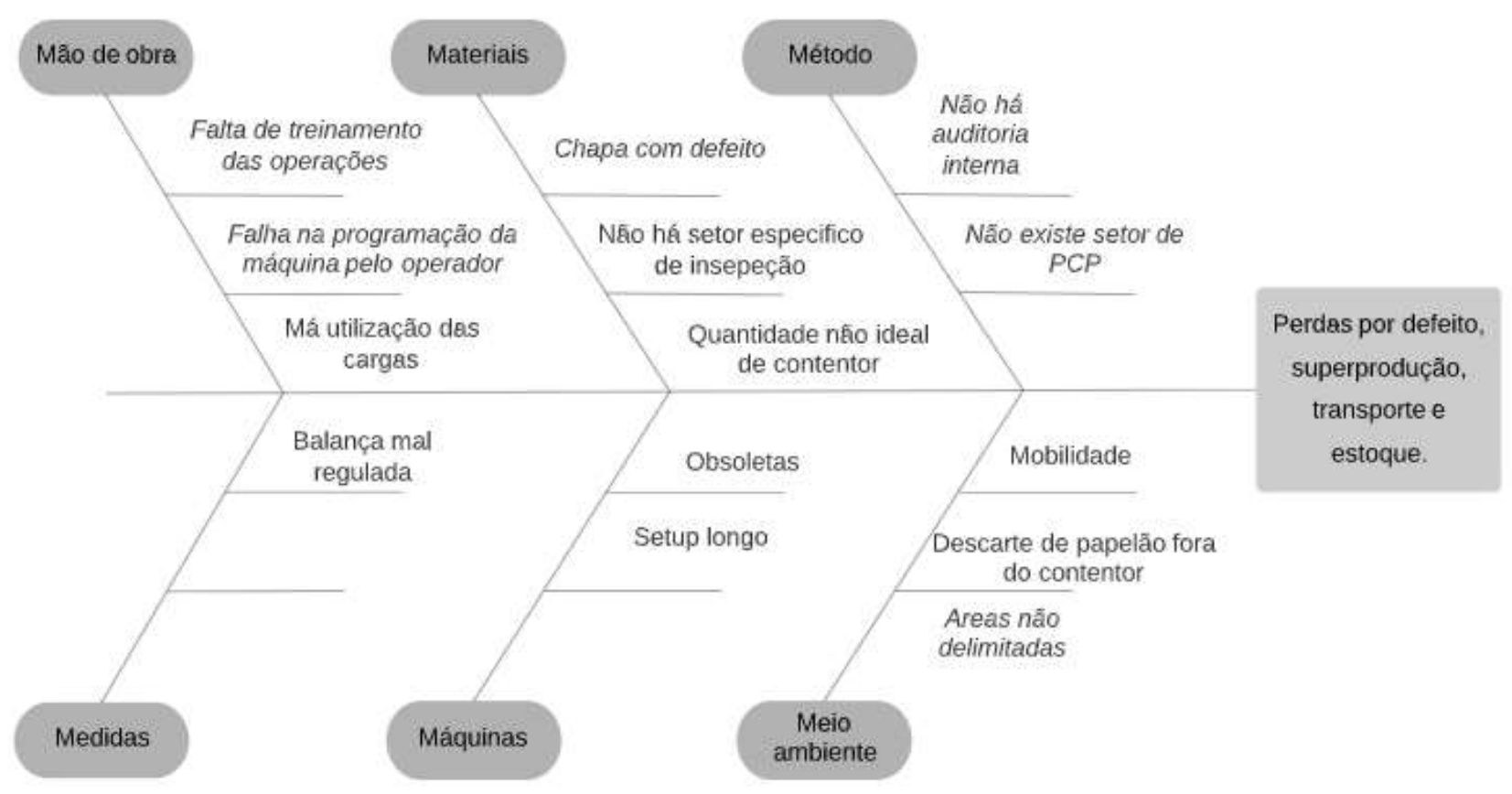

Fonte: Autores (2021).

Nas causas descritas acima, referente a perda por fabricação de produtos defeituoso foi identificado as seguintes causas: mão de obra, materiais e métodos. Foi identificado que as causas para a ocorrência dessa perda são pelo conjunto de defeitos e falta de calibração das máquinas seja na etapa de impressão, corte ou acabamentos, que provocam a geração de produtos com defeitos, juntamente com a falta de treinamento dos funcionários nos processos operacionais, e a falta de inspeções nos procedimentos e produtos.

Observou-se que na perda por superprodução suas causas estão relacionadas a mão de obra, método e máquina. Foi verificado que não há um controle efetivo da quantidade do uso da chapa de papelão, pois os operadores não são treinados com exatidão, além de não ter um planejamento de produção. Outra causa favorável é quanto a máquina, pois por ter um longo período de setup, a empresa começa a produzir mais para compensar o tempo em que a máquina ficar parada.

No problema identificado como perda por estoque foi verificado as causas: Método e máquina. Percebeu-se que há um desiquilíbrio entre a produção e a demanda, no qual faz parte do setor de Programação e Controle de Produção (PCP) controlar, mas que não está presente na empresa. Outro fator importante é a produção antecipada das caixas para gerar estoques e assim compensar esperas. 
Por fim, no problema identificado como perda por transporte foi verificado a causa do meio ambiente, pois nos centros de trabalho e nos corredores do galpão não há delimitações para circulação de pessoas e materiais, tornando o fluxo confuso e prejudicando o processo, pois a falta de padronização determinada para o fluxo das caixas dentro do processo dificulta o controle visual e a organização da fábrica como um todo, além de não ter uma sinalização nas máquinas, o que são feitas através de uma placa superior com a identificação do determinado grupo de maquinário responsável pelo processo de produção. Outro fator importante é o descarte dos refugos próximo aos centros de trabalho, no qual ocorre quando não há contentores disponíveis, fazse com que dificulta o transporte das empilhadeiras dos materiais acabados para a expedição.

Contudo, a seguir será apresentado possíveis proposições para a melhoria dessas perdas e suas causas relacionadas nesse estudo, e assim será apresentado um novo modelo de layout.

\subsection{Proposta de novo layout para reduzir os desperdícios identificados no processo produtivo}

Para atingir os objetivos desse trabalho, o novo layout deve seguir os princípios de economia de movimentos, que tem como conceito principal a noção de que não se deve fazer nada que seja desnecessário, pois no layout atual, nota-se um deslocamento exagerado da mão de obra para buscar equipamentos, ferramentas e materiais. Além de contribuir para eliminar um dos sete tipos e desperdícios citados por Ohno (1997), auxilia na ordenação dos serviços, eliminando cruzamento de materiais, mão de obra e máquinas.

Além disso, com base nas causas levantadas através do Diagrama de Ishikawa no item 3.3 foi priorizado trabalhar aquelas relacionadas aos desperdícios de maior frequência, como: falta de treinamento operacional do processo produtivo, falta de inspeção para verificação de falhas na chapa de impressão e acabamento, excesso de estoque causado pela falta de planejamento da produção e setup longo das máquinas, além mobilidade nos centros de trabalho e o descarte incorreto dos refugos.

A identificação e correção desses pontos de desperdício são essenciais para a organização reduzir custos, aumentar lucros, melhorar a capacidade de atendimento à demanda e melhorar a qualidade de seus produtos e serviços. Abaixo no Quadro 3 estão descritas algumas propostas de soluções para esses pontos. 
Research, Society and Development, v. 10, n. 7, e35710716933, 2021

(CC BY 4.0) | ISSN 2525-3409 | DOI: http://dx.doi.org/10.33448/rsd-v10i7.16933

Quadro 3 - Plano de ação.

\begin{tabular}{|c|c|c|c|c|c|}
\hline $\mathrm{O}$ que & Objetivo & Quem & Como & Quando & Onde \\
\hline $\begin{array}{l}\text { Treinamento de } \\
\text { operação }\end{array}$ & $\begin{array}{c}\text { Atuar na perda por superprodução, } \\
\text { perda por transporte e fabricação de } \\
\text { produtos defeituoso. }\end{array}$ & $\begin{array}{l}\text { Supervisor } \\
\text { responsável }\end{array}$ & $\begin{array}{l}\text { Elaborar treinamento focado na } \\
\text { falha do operador. }\end{array}$ & $\begin{array}{l}\text { Admissional e } \\
\text { periodicamente }\end{array}$ & $\begin{array}{l}\text { Sala de } \\
\text { treinamento }\end{array}$ \\
\hline $\begin{array}{l}\text { Criação da atividade de } \\
\text { inspeção de chapa de } \\
\text { papelão }\end{array}$ & $\begin{array}{c}\text { Atuar na perda por produtos } \\
\text { defeituosos }\end{array}$ & $\begin{array}{c}\text { Operador das } \\
\text { máquinas de corte } \\
\text { e impressora }\end{array}$ & $\begin{array}{l}\text { Atribuir atividade de inspeção de } \\
\text { chapas }\end{array}$ & Imediato & No galpão \\
\hline Criação do setor de PCP & $\begin{array}{c}\text { Atuar na perda por superprodução, } \\
\text { perdas por estoque, por produtos } \\
\text { defeituosos e transporte }\end{array}$ & Diretoria & $\begin{array}{l}\text { Contratar engenheiro de } \\
\text { produção }\end{array}$ & $29 / 2021$ & $\begin{array}{l}\text { Área de } \\
\text { Produção }\end{array}$ \\
\hline $\begin{array}{l}\text { Criação de Auditoria } \\
\text { Interna }\end{array}$ & $\begin{array}{c}\text { Atuar na perda por produtos } \\
\text { defeituosos }\end{array}$ & Setor de Qualidade & $\begin{array}{c}\text { Elaborar plano de auditoria com } \\
\text { requisitos especificos compondo } \\
\text { as normas já existentes da } \\
\text { qualidade }\end{array}$ & Imediato & No galpão \\
\hline $\begin{array}{c}\text { Treinamento da } \\
\text { Instrução de trabalho } \\
\text { para ajuste das máquinas }\end{array}$ & $\begin{array}{c}\text { Atuar na perda por produtos defeitusos } \\
\text { e perda por estoque }\end{array}$ & $\begin{array}{l}\text { Supervisor } \\
\text { responsável }\end{array}$ & $\begin{array}{l}\text { Aumentar a periodicidade dos } \\
\text { treinamentos de Instrução do } \\
\text { trabalho referente ao ajuste das } \\
\text { máquinas de corte, vinco e } \\
\text { impressora. }\end{array}$ & Semestralmente & $\begin{array}{l}\text { Área de } \\
\text { impressão, } \\
\text { corte e vinco }\end{array}$ \\
\hline
\end{tabular}

Fonte: Autores (2021).

Além das sugestões citadas acima, foi proposto uma mudança na disposição das máquinas, equipamentos e materiais, conforme demonstrado na Figura 4. Os paletes que estavam presentes dentro do galpão sem utilidade, foram colocados na área externa para deixar livre o espaço para a circulação das paleteiras e dos funcionários. Os estoques ficaram próximos as áreas de recepção e expedição e as máquinas ficaram agrupadas para menor movimentação dos produtos e dos funcionários.

Figura 4 - Proposta de layout.

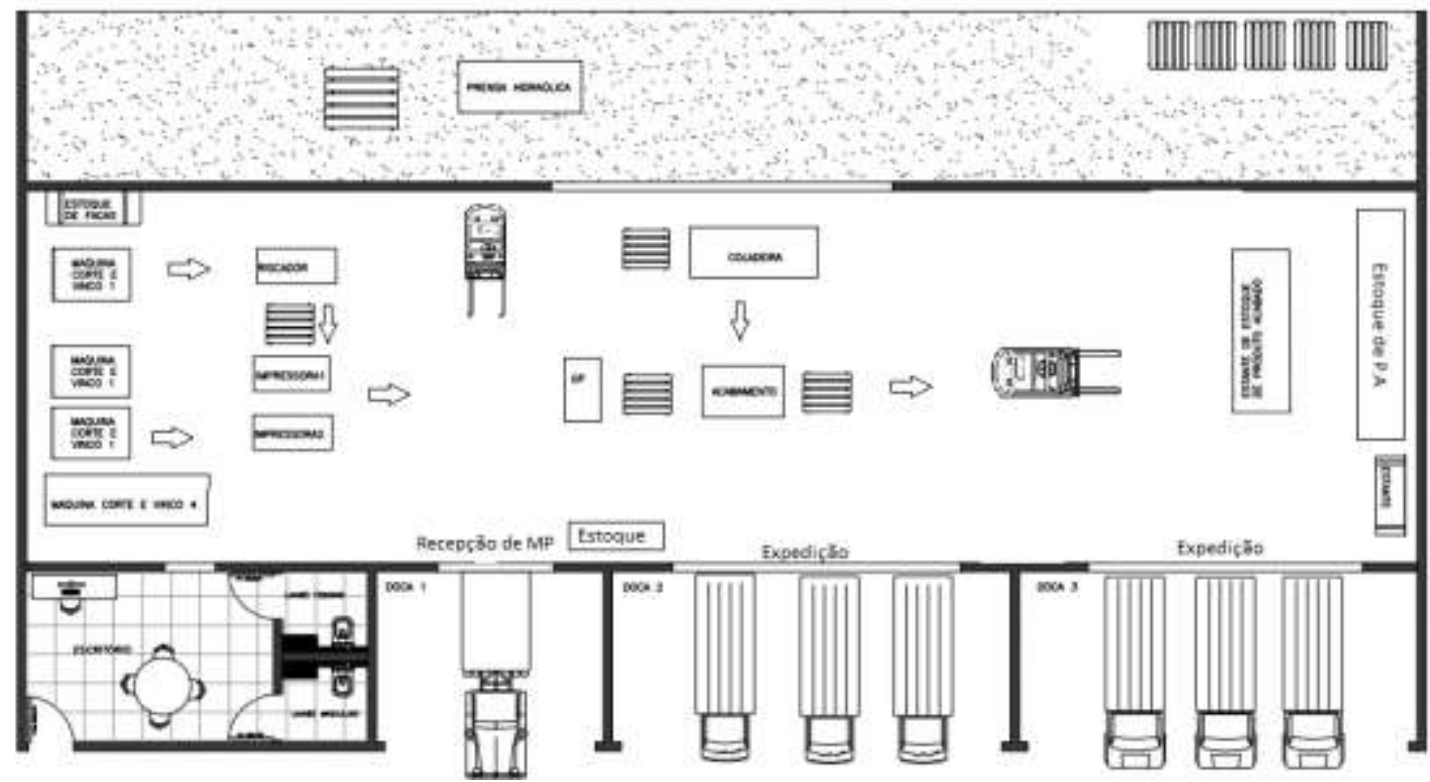

Fonte: Autores (2021). 
A modificação no layout atual poderá auxiliar a melhorar as operações como por exemplo, diminuindo a distância entre o insumo ao maquinário, o transporte desnecessário dentro da fábrica e uma menor circulação total no local.

\section{Conclusão}

Por meio da análise dos dados das visitas in loco, foi identificado um grande número de não conformidades no processo produtivo da organização. Para reduzir não conformidades e melhorar a eficácia do processo produtivo, realizamos uma pesquisa bibliográfica sobre layout e produção enxuta. Com base nesta pesquisa bibliográfica, foi proposto o método de implementação de manufatura enxuta aplicada a um novo layout, para apoiar a organização na solução desses problemas.

O layout proposto foi apresentado a uma organização de pequeno porte que integra a indústria de embalagens brasileira e que precisava aprimorar seus processos e atender às exigências do mercado. Dessa forma, a organização pode reduzir o desperdício e aumentar sua eficiência operacional e lucratividade, o que ajuda a reter os clientes existentes e conquistar novos clientes.

Com base nos resultados obtidos, pode-se concluir que a aplicação do layout proposto pode otimizar o processo produtivo, que foi evidenciado pela redução do tempo de espera e na minimização das perdas durante o processo, para isso foram utilizados ferramentas e conceitos da produção enxuta, com o propósito de identificar as oportunidades de melhoria, direcionando as ações a serem tomadas. Essas descobertas contribuem para melhorar a eficácia da organização, atendendo aos requisitos do cliente, das agências reguladoras e das próprias organizações e, assim, permite que a organização obtenha vantagens competitivas.

A implementação e aplicação do layout proposto, bem como a integração do método de manufatura enxuta, com outras ferramentas de gestão podem motivar pesquisas futuras a análise pós-implantação das alterações, identificando informações de estudos anteriores e posteriores à melhoria sugerida por este trabalho. Ao mesmo tempo, isso propicia oportunidade de um estudo comparativo da metodologia empregada em outras indústrias, de diferentes segmentos e dimensões.

\section{Referências}

Associação Brasileira de Embalagem (2019). Estudo ABRE macroeconômico e de tendências: Apresentação agosto de 2019: retrospecto do primeiro semestre de 2019. https://www.abre.org.br/dados-do-setor/ano2019

Antunes, J. et al. (2008). Sistemas de Produção: Conceitos e práticas para projeto e gestão da produção enxuta. Bookman.

Associação Brasileira de Normas Técnicas. (2002). NBR 6023: informação e documentação: referências: elaboração. ABNT.

Associação Brasileira de Normas Técnicas. (2003). NBR 6028: informação e documentação: resumo: apresentação. ABNT.

Gil, A. C. (2002). Como elaborar projetos de pesquisa. Atlas.

Gil, A. C. (2008). Métodos e Técnicas de Pesquisa Social. Atlas.

Imai, M. (2014). Gemba Kaizen: Uma abordagem de bom senso à estratégia de melhoria contínua. Bookman.

Marconi, A. M \& Lakatos M. E. (2003). Fundamentos de metodologia científica. Atlas.

Ohno, T. (1997). Sistema Toyota de Produção: Além da Produção em Larga Escala. Bookman.

Peinado, J. \& Graeml, A. (2007). Administração da Produção: Operações Industriais e de Serviços. https://issuu.com/jurandir_peinado/docs/livro2folhas/163

Prodanov, C. C. \& Freitas, E. C. (2013). Metodologia do trabalho científico: métodos e técnicas da pesquisa e do trabalho acadêmico. Novo Hamburgo. Severino, A. J. (2016). Metodologia do trabalho científico. Cortez.

Shingo, S. (2007) O Sistema Toyota de Produção: Do ponto de vista da Engenharia de Produção. Bookman.

Silva, L. E., \& Menezes, M. E. (2005). Metodologia da pesquisa e elaboração de dissertação. UFSC.

Slack, N \& Chambers, S. \& Johnston, R. (2002) Administração da Produção. Atlas. 
Research, Society and Development, v. 10, n. 7, e35710716933, 2021

(CC BY 4.0) | ISSN 2525-3409 | DOI: http://dx.doi.org/10.33448/rsd-v10i7.16933

Soares, M. (2019). Setor de embalagens deve crescer ainda mais até 2024 de acordo com o termômetro do mercado. https://www.fiesp.com.br/noticias/setorde-embalagens-deve-crescer-ainda-mais-ate-2024-de-acordo-com-termometro-do-mercado/

Vânia, S. G. et al. (2019). Implantação de Um Novo Layout Produtivo em Uma Empresa do Setor de Lubrificantes e Desengraxantes. Research, Society and Development, 8, (5), e2385939. https://rsdjournal.org/index.php/rsd/article/view/939

Vergara, S. C. (2016). Projetos e relatórios de pesquisa em administração. Atlas.

Werkema, C. (2013). Métodos PDCA e DMAIC e suas ferramentas analíticas. Elsevier.

Yin, R. K. (2001). Estudo de caso: planejamento e métodos. Bookman.

Zanella, L. C. H. (2009) Metodologia de estudo e de pesquisa em administração. Florianópolis: Departamento de Ciências da Administração / UFSC. https://www2.unifap.br/claudiomarcio/files/2015/12/LIVRO-Metodologia-de-Estudo-e-Pesquisa-em-Administração.pdf 